\title{
Comparative morbidity of ablative energy-based salvage treatments for radio-recurrent prostate cancer
}

\author{
Khurram M. Siddiqui, MBBS, MSc, FRCS, FEBU; Michele Billia, MD; ; \\ Andrew Williams, BMedSc, MBChB, FRACS, ${ }^{*}$ Ali Alzahrani, MD,* Joseph L. Chin, MD, FRCSC \\ *Western University, London, ON; *Department of Urology, University of Dammam, Saudi Arabia
}

See related commentary on page 330.

Cite as: Can Urol Assoc J 2015;9(9-10):325-9. http://dx.doi.org/10.5489/cuaj.3113

Published online October 13, 2015.

\section{Abstract}

Introduction: We compared the morbidity of whole gland salvage ablation using cryotherapy (CRYO) and high-intensity focused ultrasound (HIFU) for radio recurrent prostate cancer at a single centre over a 17-year period.

Methods: Patients were divided in 3 cohorts. Group 1 included the first 65 patients treated with CRYO (1995-1998); Group 2 included the last 65 patients treated with CRYO (2002-2004), and Group 3 included 65 patients treated with HIFU (2006-2011). We analyzed the complications reported within at least 90 days of treatment or up to the last follow-up.

Results: We tallied Clavien grade complications. For Groups 1, 2 and 3, we recorded the following Clavien I-II complications: 78, 49 and 13, respectively. For Clavien grade IIIa, 2, 5 and 4 for Groups 1, 2 and 3, respectively. For Clavien grade IIIb, 8, 2 and 3 for Groups 1, 2 and 3, respectively. Clavien grade II complications were statistically higher in Group 1 versus Group $2(p=0.005)$ and in Group 2 versus Group 3 ( $p=0.0001$ ). The rate of mild-moderate incontinence was significantly higher in the CRYO group compared to the HIFU cohort $(p \leq 0.05)$. The rate of urinary retention was significantly higher in Group 2 compared to Group 3 ( $p=0.0005)$. The rates of severe incontinence (range: $1.5 \%-5 \%$ ), need for surgical intervention (uniform at $1.5 \%$ ), and recto-urethral fistulae (range: $1.5 \%-3 \%$ ) were not statistically different.

Conclusions: CRYO was associated with higher overall morbidity. The morbidity during the early experience with HIFU was lower than both subgroups of CRYO. This may reflect the advancement of technology or cumulative learning experience.

\section{Introduction}

Treatment for local persistence or recurrence of prostate cancer after radiation therapy poses a unique challenge. ${ }^{1}$ In

spite of improvement in the morbidity profile in contemporary salvage prostatectomy series, a significant proportion of patients, especially the elderly and those with significant medical comorbidities, are suboptimal candidates for salvage prostatectomy. ${ }^{2}$ Energy-based salvage treatment modalities, such as high-intensity focused ultrasound (HIFU) and cryotherapy (CRYO), are minimally invasive ablative options which have a more favourable side effect profile. ${ }^{3-5}$ At our centre we have been treating radio-recurrent prostate cancer (RRPC) with both these energy-based modalities, transitioning from CRYO to HIFU. ${ }^{6-9}$ We report our single centre and single surgeon (17 years) experience to highlight the learning curve and compare the morbidity of the two salvage treatment modalities.

\section{Methods}

Institutional ethics board approval was obtained and 283 patients were prospectively enrolled for minimally invasive energy-based salvage treatment from 1995 to 2014. This included 187 patients who underwent salvage CRYO (1995-2004) and 96 patients who underwent salvage HIFU (2006-2011). In 2004, we transitioned from offering CRYO to HIFU as salvage treatment for RRPC. For the current analysis, we excluded patients with less than 1 year follow-up and those enrolled for a Food and Drug Administrationsponsored HIFU trial from which the data are quarantined.

We divided our patients into 3 groups: Group 1 included the initial 65 patients treated with CRYO between 1995 and 1998 (the "early CRYO group"); Group 2 included the last 65 patients treated with CRYO from 2002 to 2004 (after accumulating experience with 150 cryoablation cases) (the "later CRYO group"); and Group 3 included 65 patients who underwent HIFU from 2004 to 2012. This group-wise comparison was designed to elucidate the impact of the learning curve and technologic transit, and to compare the two modalities in terms of morbidity profile as salvage treatments for RRPC, without inter-operator and inter-institutional variability.

The Candella system (Candella,Wayland, MA) was used for the first 11 patients and the CRYOCARE CS (Endocare, 
Siddiqui et al.

Austin, TX) was used for all subsequent patients. In total, 5 to 6 cryoprobes were placed transperineally under transrectal ultrasound guidance. A 3-dimensional ultrasound system developed at our institution was used to guide and verify cryoprobe placement. ${ }^{10,11}$ Two freeze-thaw cycles were employed. Monitoring was achieved by visualization of the "ice ball" on ultrasound and temperature recordings from 3 thermocouples placed at the left and right neurovascular bundles and in the midline near the apex of the prostate, respectively. A urethral warming device (Cook Urological, Spencer, IN) was used. In all patients a suprapubic catheter was placed intra-operatively and retained for 3 weeks. No patient in either group underwent a pre-salvage transurethral resection of the prostate.

HIFU treatment was performed using the Sonablate 500 machine (SonaCare Medical, Charlotte, NC). Treatment planning was based on whole gland ablation with a nonnerve sparing approach. Continuous rectal temperature recording was carried out by monitoring the reflective index of the rectal wall. In all patients a suprapubic catheter was placed intra-operatively and retained for 3 weeks.

We recorded preoperative clinical data, including age, prostate-specific antigen (PSA), and Gleason score. Morbidity data were obtained at follow-up visits at regular intervals by the operating surgeon for at least 1 year. Patients living more than $300 \mathrm{~km}$ from the hospital were followed by their respective local urologists, who were contacted for any complications and clinical sequelae. Incontinence was defined as mild-moderate if the patient required only 0 to1 pads, and as "severe" if 2 or more pads were needed. "Incontinence requiring surgery" was defined as any incontinence problems requiring any form of surgical intervention. Gross hematuria and perineal pain were classified under self-reported complications. Bladder neck contracture, urinary retention, urinary tract infection, and fistula were all physician-recorded variables at follow-up appointments and/ or extracted from hospital records. We compared all complications reported during at least 90 days of treatment or up to the last follow-up.

Data were extrapolated from prospectively maintained databases, completed daily by the research coordinator. We used a one-way ANOVA test to compare the distribution of central tendency of the 3 groups. Student's t-test was used to compare groups. The Fisher exact test was used to compare the morbidity (categorical data) profile among the subgroups. Statistical significance was set at $p<0.05$.

\section{Results}

The mean age was significantly higher in Group 1 compared to Group $2(p=0.001)$, although there was no difference between Group 1 and Group 3 ( $p=0.10$ ) or between Group 2 and Group $3(p=0.41)$. The mean pre-salvage PSA was

\begin{tabular}{|c|c|c|c|c|}
\hline & $\begin{array}{c}\text { Group } 1 \\
\text { Cryotherapy } \\
(1995-1998) \\
(n=65)\end{array}$ & $\begin{array}{c}\text { Group } 2 \\
\text { Cryotherapy } \\
(2002-2004) \\
(n=65)\end{array}$ & $\begin{array}{c}\text { Group 3 } \\
\text { HIFU } \\
(2006-2011) \\
(n=65)\end{array}$ & $\begin{array}{c}\boldsymbol{p} \text { value } \\
\text { (one-way ANOVA) }\end{array}$ \\
\hline Age (mean) & $68.59 \pm 6.65$ & $71.68 \pm 6.79$ & $70.65 \pm 7.54$ & 0.04 \\
\hline Pre-salvage PSA (mean) & $9.38 \pm 7.03$ & $3.25 \pm 2.33$ & $3.86 \pm 3.01$ & $0.0001^{*}$ \\
\hline \multicolumn{5}{|l|}{ Pre-salvage Gleason score } \\
\hline$\leq 6$ & 9 & 18 & 10 & \\
\hline 7 & 22 & 17 & 28 & \\
\hline 8 & 13 & 13 & 12 & \\
\hline 9 & 4 & 4 & 2 & \\
\hline 10 & 4 & 1 & 1 & \\
\hline NC & 13 & 12 & 12 & \\
\hline \multicolumn{5}{|l|}{ Pre-RT T stage or D'Amico risk } \\
\hline T1 & 7 & 10 & & \\
\hline $\mathrm{T} 2$ & 38 & 30 & & \\
\hline T3 & 6 & 6 & & \\
\hline NA & 14 & 19 & & \\
\hline \multicolumn{5}{|l|}{ Pre-RT D'Amico risk } \\
\hline Low risk & & & $19(29 \%)$ & \\
\hline Intermediate risk & & & $34(52 \%)$ & \\
\hline High risk & & & $12(19 \%)$ & \\
\hline \multicolumn{5}{|l|}{ Type of radiation } \\
\hline EBRT & 63 & 65 & 61 & \\
\hline BT & 2 & 0 & 4 & \\
\hline Adjuvant hormone therapy & $9(13 \%)$ & $12(18 \%)$ & $14(21 \%)$ & \\
\hline
\end{tabular}




\begin{tabular}{|c|c|c|c|}
\hline Morbidity & $\begin{array}{c}\text { Group } 1 \\
\text { Cryotherapy } \\
(1995-1998) \\
(n=65)\end{array}$ & $\begin{array}{c}\text { Group } 2 \\
\text { Cryotherapy } \\
(2002-2004) \\
(n=65)\end{array}$ & $\begin{array}{c}p \text { value } \\
\text { (Fisher's } \\
\text { exact test) }\end{array}$ \\
\hline $\begin{array}{l}\text { Incontinence mild- } \\
\text { moderate }\end{array}$ & $32(49 \%)$ & $20(31 \%)$ & 0.048 \\
\hline Perineal pain & $12(18 \%)$ & $7(10 \%)$ & 0.320 \\
\hline Urinary retention & $18(27 \%)$ & $14(21 \%)$ & 0.54 \\
\hline Gross hematuria & $8(12 \%)$ & $5(7 \%)$ & 0.56 \\
\hline Urinary tract infection & $8(12 \%)$ & $3(5 \%)$ & 0.206 \\
\hline Severe incontinence & $1(1.5 \%)$ & $3(5 \%)$ & 0.619 \\
\hline Recto-urethral fistula & $1(1.5 \%)$ & $2(3 \%)$ & 1.0 \\
\hline $\begin{array}{l}\text { Incontinence requiring } \\
\text { surgery }\end{array}$ & $1(1.5 \%)$ & $1(1.5 \%)$ & 1.0 \\
\hline $\begin{array}{l}\text { Bladder neck } \\
\text { contracture/stricture }\end{array}$ & 7 (10\%) & $1(1.5 \%)$ & 0.061 \\
\hline
\end{tabular}

significantly higher in Group 1 compared to both Groups 2 and $3(p=0.001)$. The number of patients with Gleason score $>8$ were also higher in Group 1 (21, 18 and 15 in Group 1, 2 and 3 respectively) (Table 1).

We tallied the pre-radiation $\mathrm{T}$ stage for cryotherapy patients and the D'Amico risk category ${ }^{12}$ for HIFU patients (Table 1). Most patients underwent external beam radiation therapy (EBRT). Brachytherapy (BT) alone was the primary curative therapy for $3 \%, 0 \%$ and $6 \%$ of patients in Groups 1 , 2 and 3, respectively. No patients experienced any RTOG/ EORTC (Radiation Therapy Oncology Group/European Organization for Research and Treatment of Cancer) late radiation morbidity. ${ }^{13}$ Of the patients, $13 \%, 18 \%$ and $21 \%$ from Groups 1, 2 and 3, respectively, received adjuvant androgen deprivation. The oncological outcomes of our series have previously been reported. ${ }^{7-9}$

We tallied Clavien grade complications. For Groups 1, 2 and 3, we recorded the following Clavien I-II complications: 78, 49 and 13, respectively. For Clavien grade IIla, 2, 5 and 4 for Groups 1, 2 and 3, respectively. For Clavien grade IIIb, 8, 2 and 3 for Groups 1, 2 and 3, respectively. ${ }^{14}$ There was one Clavien grade 4a complication in Group 3, resulting from a blocked supra-pubic catheter causing intraperitoneal bladder rupture requiring laparotomy. Clavien grade II complications were statistically higher in Group 1 versus Group $2(p=0.005)$ and in Group 2 versus Group $3(p=0.0001)$.

We tallied the complication rates in Group 1 (early CRYO) and Group 2 (later CRYO) (Table 2). There was a significantly higher rate of mild-moderate incontinence in Group 1 $(p=0.04)$. We also compared Group 1 (early CRYO) and Group 3 (HIFU) (Table 3). There was a significantly higher rate of mild-moderate incontinence $(p=0.0001)$, perineal pain $(p=0.025)$, and urinary retention $(p=0.0001)$ in the

\begin{tabular}{|c|c|c|c|}
\hline Morbidity & $\begin{array}{c}\text { Group } 1 \\
\text { Cryotherapy } \\
(1995-1998) \\
(n=65)\end{array}$ & $\begin{array}{c}\text { Group } 3 \\
\text { HIFU } \\
(2006-2011) \\
(n=65)\end{array}$ & $\begin{array}{c}p \text { value } \\
\text { (Fisher's } \\
\text { exact test) }\end{array}$ \\
\hline $\begin{array}{l}\text { Incontinence mild- } \\
\text { moderate }\end{array}$ & $32(49 \%)$ & $2(3 \%)$ & 0.0001 \\
\hline Perineal pain & $12(18 \%)$ & $3(5 \%)$ & 0.0253 \\
\hline Urinary retention & $18(27 \%)$ & $1(1.5 \%)$ & 0.0001 \\
\hline Gross hematuria & $8(12 \%)$ & $4(6 \%)$ & 0.3642 \\
\hline Urinary tract infection & $8(12 \%)$ & $3(5 \%)$ & 0.2061 \\
\hline Severe incontinence & $1(1.5 \%)$ & $2(3 \%)$ & 1.00 \\
\hline Recto-urethral fistula & $1(1.5 \%)$ & $2(3 \%)$ & 1.00 \\
\hline $\begin{array}{l}\text { Incontinence requiring } \\
\text { surgery }\end{array}$ & $1(1.5 \%)$ & $1(1.5 \%)$ & 1.00 \\
\hline $\begin{array}{l}\text { Bladder neck } \\
\text { contracture/stricture }\end{array}$ & $7(10 \%)$ & $2(3 \%)$ & 0.1643 \\
\hline Laparotomy & 0 & 1 & 1.00 \\
\hline
\end{tabular}

early CRYO group compared to the HIFU cohort. The rate of morbidity was compared between Group 2 (later CRYO) and Group 3 (HIFU) (Table 4). The rate of mild-moderate incontinence was significantly higher in the later CRYO group compared to the HIFU group $(p=0.0001)$. Similarly, the rate of urinary retention was significantly higher in the later CRYO compared to the HIFU group $(p=0.0005)$. Other complications, including severe incontinence, incontinence requiring surgical intervention and recto-urethral fistulae, were not statistically different.

Overall, there were less complications in the HIFU group $(n=20)$ compared to the early CRYO group $(n=88)$ and the later CRYO group $(n=56)$. This difference was statistically significant in group-wise comparison $(p=0.05)$.

\section{Discussion}

About 25\% of North American men with newly diagnosed clinically localized prostate cancer choose RT-based therapies as their primary treatment, including EBRT and BT. ${ }^{15}$ Although dose intensification and improved technologies of RT improve outcomes, almost 1 in 3 patients still experience treatment failure. ${ }^{16}$ In a proportion of these men, recurrent or persistent disease is isolated to the prostate gland only. In a series of 4839 patients, Kuban and colleagues reported $416(8.6 \%)$ cases of isolated intra-prostatic failure after RT. ${ }^{17}$ These patients may be candidates for local salvage treatment with curative intent. Although salvage radical prostatectomy is usually the preferred definitive treatment, the patient's ability to withstand the anesthesia and potential perioperative morbidity are major determinants in the choice of salvage treatment. Salvage radical prostatectomy may not be a viable option for elderly and infirmed patients. ${ }^{1}$ 
Siddiqui et al.

\begin{tabular}{|c|c|c|c|}
\hline Morbidity & $\begin{array}{c}\text { Group } 2 \\
\text { Cryotherapy } \\
(2002-2004) \\
(n=65)\end{array}$ & $\begin{array}{c}\text { Group } 3 \\
\text { HIFU } \\
(2006-2011) \\
(n=65)\end{array}$ & $\begin{array}{c}p \text { value } \\
\text { (Fisher's } \\
\text { exact test) }\end{array}$ \\
\hline $\begin{array}{l}\text { Incontinence mild- } \\
\text { moderate }\end{array}$ & $20(31 \%)$ & $2(3 \%)$ & 0.0001 \\
\hline Perineal pain & $7(10 \%)$ & $3(5 \%)$ & 0.3241 \\
\hline Urinary retention & $14(21 \%)$ & $1(1.5 \%)$ & 0.0005 \\
\hline Gross hematuria & $5(7 \%)$ & $4(6 \%)$ & 1.00 \\
\hline Urinary tract infection & $3(5 \%)$ & $3(5 \%)$ & 1.00 \\
\hline Severe incontinence & $3(5 \%)$ & $2(3 \%)$ & 1.00 \\
\hline Recto-urethral fistula & $2(3 \%)$ & $2(3 \%)$ & 1.00 \\
\hline $\begin{array}{l}\text { Incontinence requiring } \\
\text { surgery }\end{array}$ & $1(1.5 \%)$ & $1(1.5 \%)$ & 1.00 \\
\hline $\begin{array}{l}\text { Bladder neck } \\
\text { contracture/stricture }\end{array}$ & $1(1.5 \%)$ & $2(3 \%)$ & 1.00 \\
\hline Laparotomy & 0 & 1 & 1.00 \\
\hline
\end{tabular}

Minimally invasive modalities, such as CRYO and HIFU, have been used as salvage treatment options. We have reported, based on our experience on 176 patients, a 10-year disease-free survival (DFS) of $39 \%$ for salvage CRYO. ${ }^{7}$ For salvage HIFU, we reported 1- and 2-year progression-free survival rates of $62 \%$ and $48 \%$, respectively. ${ }^{9}$ For low-risk prostate cancer, Murat and colleagues reported the DFS rate of $53 \%$ for salvage HIFU at 40 months of follow-up. ${ }^{18}$ At 7 years, Crouzet and colleagues reported a cancer-specific and metastasis-free survival rate of $80 \%$ and $79.6 \%$, respectively. ${ }^{19}$ Given the reasonable oncologic outcome in the management of RRPC with these modalities, minimizing treatment-related morbidity becomes more of a clinical priority. ${ }^{20}$ Concerns relating to morbidity from energybased salvage ablation modalities may be one reason why such treatments have remained underutilized. ${ }^{21}$ We present a comparative account of the morbidity profile for these minimally invasive options for whole gland energy based ablation of RRPC.

Several series on complications of salvage CRYO report incontinence rates from $4.4 \%$ to $13 \%{ }^{22,23}$ Ahmad and colleagues (CROP trial) in their cohort of 283 patients reported an incontinence rate of $12 \%\left(0-1 \mathrm{pad} /\right.$ day). ${ }^{22}$ In our experience we found a higher rate of mild-moderate incontinence ( $\leq 1 \mathrm{pad} /$ day) $49 \%, 31 \%$ and $3 \%$ in Groups 1,2 and 3 , respectively; for severe incontinence ( $>2 \mathrm{pad} /$ day), we reported a similar rate $(1.5 \%, 5 \%$ and $3 \%)$ for Groups 1 , 2 and 3, respectively. Pisters and colleagues reported in a comparable sized series $4.4 \%$ (defined as incontinence requiring use of pads), which is commensurate with our results. ${ }^{23}$ The all-grade incontinence in patients treated with HIFU in our cohort was $6 \%$. Crouzet and colleagues reported a $19.5 \%$ incontinence rate in 290 patients treated with HIFU for RRPC..$^{19}$ This difference may be attributed to different definitions of incontinence, variations in surgical technique or technology (Ablatherm HIFU [Maple Leaf Inc.] or Sonablate HIFU), and in patient selection. We found an improvement in mild-moderate incontinence in the later CRYO group compared to the early CRYO group ( $p=0.048$ ). This may be attributed to the learning curve or refinement in the patient selection process. Further improvement was seen in the HIFU group compared to the later CRYO group $(p=0.0001)$, which again, may be reflect the continuation of the learning curve, improvement of technology or both. Since incontinence is one of the most problematic complications associated with salvage treatment, we believe HIFU is a significant addition to the therapeutic armamentarium for localized RRPC.

Recto-urethral fistula is the most serious complication in the local salvage treatment of RRPC. We report an incidence of $1.5 \%$ to $3 \%$ in the 3 groups. Similar rates of ranging from $1.8 \%$ to $6 \%$ have also been reported. ${ }^{24}$ The rectal injury rates from large centres with experienced surgeons for salvage RRP range from $0.3 \%$ to $6 \%{ }^{25}$

The mean age in our 3 groups was 70.3 years and all our patients had earlier undergone radiotherapy with curative intent. Most CRYO patients reported pre-existing erectile dysfunction (ED) on a non-validated questionnaire. The mean pre-HIFU International Index of Erectile Function (IIEF) score was $8.6 \pm 7.9$. Therefore, these patients were not candidates for the nerve-sparing salvage ablation protocol. At 45,90 , and 180 days post-HIFU, the IIEF scores were $3.4 \pm 4,5.1 \pm 5,5.4 \pm 6.5$, respectively. With the advances in magnetic resonance imaging technology, it is now possible to delineate the focus of RRPC and we believe that focal salvage may be a viable treatment option for selected potent men with RRPC.

Although the pre-salvage PSA of Group 1 patients (initial CRYO) was significantly higher $(p \leq 0.001)$, we do not believe it would have affected the complication rate. The lower mean PSA level likely implied a lower local tumour volume, suggesting a more stringent patient selection process. An improvement in patient selection, in turn, may have contributed to the lower complication rate.

In this study there has been a statistically significant reduction in the rate of Clavien grade I-II complications and this likely indicated a learning curve, although validation from other institutions would be required for confirmation.

The single-centre, single-surgeon experience is a limitation, although it provided consistency and perhaps more adequately demonstrated the effect of the learning curve and transition of technology on morbidity based on cumulative experience. Another key limitation is the retrospective design, as this methodology of comparison is considered suboptimal; however, the accrual of patients for a trial randomizing patients to different salvage minimally invasive procedures was impractical. 


\section{Conclusion}

Salvage HIFU shows promise as a further advance in the management of RRPC. This modality is associated with a low complication rate, including mild-moderate incontinence and urinary retention as compared to CRYO. The complication rate of salvage CRYO decreased with increasing surgeon experience. The morbidity during the early experience with HIFU was lower than both subgroups of CRYO. This may reflect advances in technology or cumulative learning experience. Patients presenting with RRPC who are suboptimal surgical candidates for salvage radical prostatectomy may be suitable for either CYRO or HIFU.

Competing interests: The authors all declare no competing financial or personal interests. Dr. Chin is a member of the advisory boards for US HIFU and Profound Medical, Inc.

This paper has been peer-reviewed.

\section{References}

1. Touma NJ, Izawa Jl, Chin JL. Current status of local salvage therapies following radiation failure for prostate cancer. J Urol 2005;173:373-9. http://dx.doi.org/10.1097/01.ju.0000150627.68410.4d

2. Chade $D C$, Eastham J, Graefen $M$, et al. Cancer control and functional outcomes of salvage radical prostatectomy for radiation-recurrent prostate cancer: A systematic review of the literature. Eur Urol 2012;61:961-71. http://dx.doi.org/10.1016/i.eururo.2012.01.022

3. Kanthabalan A, Arya M, Punwani S, et al. Role of focal salvage ablative therapy in localised radiorecurrent prostate cancer. World J Urol 2013;6:1361-8. http://dx.doi.org/10.1007/s00345-013-1 100-9

4. Chin JL, Pautler SE, Mouraviev V, et al. Results of salvage cryoablation of the prostate after radiation: Identifying predictors of treatment failure and complications. J Urol 2001;165:1937-1942. http:// dx.doi.org/10.1016/S0022-5347(05)66246-5

5. Chalasani V, Martinez CH, Lim D, et al. Salvage HIFU for recurrent prostate cancer after radiotherapy. Prostate Cancer Prostatic Dis 2009;12:124-9. hitp://dx.doi.org/10.1038/pcan.2008.53

6. $\mathrm{Ng}$ CK, Moussa M, Downey DB, et al. Salvage cryoablation of the prostate: Follow up and analysis of predictive factors for outcome. J Urol 2001;178:1253-7. http://dx.doi.org/10.1016/i.juro.2007.05.137

7. Williams AK, Martínez CH, Lu C, et al. -Disease-free survival following salvage cryotherapy for biopsyproven radio-recurrent prostate cancer. Eur Urol 2011;60:405-10. http://dx.doi.org/10.1016/i. eururo.2010.12.012

8. Ahmed HU, Cathcart P, Chalasani V, et al. Whole-gland salvage high-intensity focused ultrasound therapy for localized prostate cancer recurrence after external beam radiation therapy. Cancer 2012; 118:3071-8. http://dx.doi.org/10.1002/cncr.26631

9. Yutkin V, Ahmed HU, Donaldson I, et al. Salvage high-intensity focused ultrasound for patients with recurrent prostate cancer after brachytherapy. Urology 2014;84:1157-1162. http://dx.doi.org/10.1016/i. urology.2014.06.054
10. Chin LL, Downey DB, Onik G, et al. Three-dimensional prostate ultrasound and its application to cryosurgery. Tech Urol 1996;2:187-193.

11. Chin JL, Downey DB, Mulligan M, et al. Three-dimensional transrectal ultrasound guided cryoablation for localized prostate cancer in nonsurgical candidates: A feasibility study and report of early results. J Urol 1998;159:910-14. http://dx.doi.org/10.1016/S0022-5347(01)63769-8

12. D'Amico AV, Whittington R, Malkowicz SB, et al. Biochemical outcome after radical prostatectomy, external beam radiation therapy, or intersititial radiation therapy for clinically localized prostate cancer. JAMA 1998;280:969-974. http://dx.doi.org/10.1001/jama.280.11.969

13. Cox JD, Stetz J, Pajak TF. Toxicity criteria of the Radiation Therapy Oncology Group (RTOG) and the European Organization for Research and Treatment of Cancer (EORTC). Int I Radiat Oncol Biol Phys 1995;31:1341-6. http://dx.doi.org/10.1016/0360-3016(95)00060-C

14. Dindo D, Demartines N, Clavien PA. Classification of surgical complications: A new proposal with evaluation in a cohort of 6336 patients and results of a survey. Ann Surg 2004;240:205-213. http://dx.doi. org/10.1097/01.sla.0000133083.54934.

15. Cooperberg MR, Broering JM, Carroll PR. Time trends and local variation in primary treatment of localized prostate cancer. J Clin Oncol 2010;28:1117-1123. http://dx.doi.org/10.1200/JC0.2009.26.0133ae

16. Zelefsky MJ, Yamada Y, Fuks Z, et al. Long-term results of conformal radiotherapy for prostate cancer: Impact of dose escalation on biochemical tumor control and distant metastases-free survival outcomes. Int J Radiat Oncol Biol Phys 2008;71:1028-1033. http://dx.doi.org/10.1016/i.ijrobp.2007.11.066

17. Kuban DA, Thames HD, Levy LB, et al. Long-term multi-institutional analysis of stage Tl-T2 prostate cancer treated with radiotherapy in the PSA era. Int J Radiat Oncol Biol Phys 2003;57:915-928. http://dx.doi. org/10.1016/S0360-3016(03)00632-1

18. Murat FJ, Poissonnier L, Rabilloud M, et al. Mid-term results demonstrate salvage high-intensity focused ultrasound as an effective and acceptably morbid salvage treatment option for locally radio-recurrent prostate cancer. Eur Urol 2009;55:640-7. hittp://dx.doi.org/10.1016/i.eururo.2008.04.091

19. Crouzet $S$, Murat FJ, Pommier P, et al. Locally recurrent prostate cancer after initial radiation therapy: Early salvage high-intensity focused ultrasound improves oncologic outcomes. Radiother Oncol 2012;105:198202. hitp://dx.doi.org/10.1016/i.radonc.2012.09.014

20. Alongi F, De Bari B, Campostrini F, et al. Salvage therapy of intraprostatic failure after radical externalbeam radiotherapy for prostate cancer: A review. Crit Rev Oncol Hematol 2013;88:550-563. http:// dx.doi.org/10.1016/i.critrevonc.2013.07.009

21. Tran H, Kwok J, Pickles T, et al. Use of energy based ablation for RRPC still remains underutilized. Urol Oncol 2014;32:701-706. http://dx.doi.org/10.1016/i.urolonc.2013.12.014

22. Ahmad I, Kalna $G$, Ismail $M$, et al. Prostate gland lengths and iceball dimensions predict micturition functional outcome following salvage prostate cryotherapy in men with radiation recurrent prostate cancer. PLoS One 2013;8:e69243. http://dx.doi.org/10.1371/journal.pone.0069243

23. Pisters LL, Rewcastle JC, Donnelly BJ, et al. Salvage prostate cryoablation: Initial results from the cryo on-line data registry. J Urol 2008;180:559-563. http://dx.doi.org/10.1016/i.juro.2008.04.005

24. Gelet A, Chapelon JY, Poissonnier L, et al. Local recurrence of prostate cancer after external beam radiotherapy: Early experience of salvage therapy using high-intensity focused ultrasonography. Urology 2004;63:625-9. http://dx.doi.org/10.1016/j.urology.2004.01.002

25. Rosoff IS, Savage SJ, Prasad SM. Salvage radical prostatectomy as management of locally recurrent prostate cancer: Outcomes and complications. World I Urol 2013;31:1347-1352. http://dx.doi. org/10.1007/s00345-013-1029-z

Correspondence: Dr. Joseph Chin, Western University, London, 0N; joseph.chin@lhsc.on.ca 